\title{
Aqua depicta III
}

\section{Representation of water in art and science}

\author{
Matilde Macagno
}

Em. Prof. University of Iowa

In this, the third paper on representation of water throughout history by artists on one side and by scientists and engineers on the other, the emphasis will be on waves influenced by different kinds of boundaries and by obstacles. I will deal mainly with water waves, as they approach fixed boundaries or bodies; some comments about waves around bodies that move relative to the water will also be included.

Among the waterscapes that have attracted many artists are those of the sea near to or at the shore. One reason for this is surely that a great variety of beautiful and, sometimes, spectacular phenomena are found there ; another is that they can be safely depicted from firm ground while including also other elements like land, ships, buildings, people. Some painters have depicted calmer scenes in the open sea and, just a few, violent storms.

Given the point of view adopted for this series of articles, it seems appropriate to convey some notions of the general behavior of water waves as they approach the coast line and finally arrive upon the varied forms of land bordering the sea (figs. 12). If there are islands, rocks, fiords, estuaries, or, in a smaller scale, ships, breakwaters, harbors, a great variety of hydrodynamic responses take place and the same oncoming waves can end up producing entirely different patterns. It helps, in understanding such effects, to resort to analogies with other wave phenomena. Most of the terminology about propagation, reflection, refraction, and diffraction of waves is shared by optics, acoustics, electricity and hydrodynamics. Already in the seventeenth century, Robert HоOKE, in his Micrograpbia [1667], compared the propagation of light from a point source to the waves propagating from the point at which a stone sank into the water. One must be careful, however, because in fact the - optics - of water waves is more complex.

In this article, I will consider water waves approaching a wall and a beach, and going around islands or ships, as well as those produced by moving ships and other objects. Not all the illustrations that are desirable can be included, and I will in some cases refer the reader to either writings or paintings in which more information can be found.

\section{Waves approaching a wall}

As a first instance of waves arriving at a fixed boundary, I will consider a wall that presents to the water a well defined plane. The case of a vertical wall is the simplest, especially when the oncoming wave propagates perpendicular to the obstacle. I will assume that the water, near and at the wall, is deep compared with the wave length. To understand what happens to waves that arrive upon such a boundary, some notions discussed in the

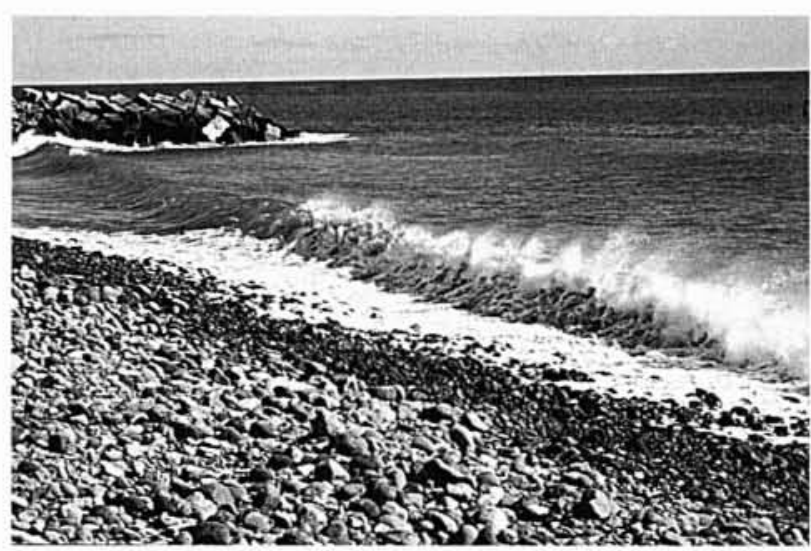

1. Waves arriving at a rocky beach in Réunion Islands. Courtesy of M. Manoha, EDF, Chatou Laboratory.

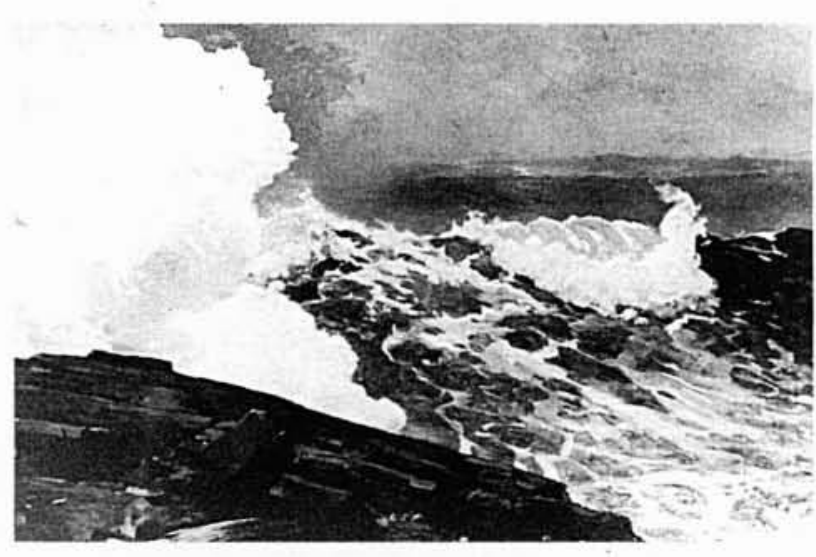

2. Waves breaking at the sea shore. Northeaster, painting by Winslow Homer, 1895. The Metropolitan Museum of Art, Gift of George A. Hearn, 1910.

second article will be very useful. The wall behaves like a mirror, and the oncoming wave is reflected back; therefore, we will have not only an incident wave but also a reflected wave, as shown in figure 3. This is then a case of superposition of waves. Under different conditions, such a phenomenon was already considered in the second article of this series. The motion of the 


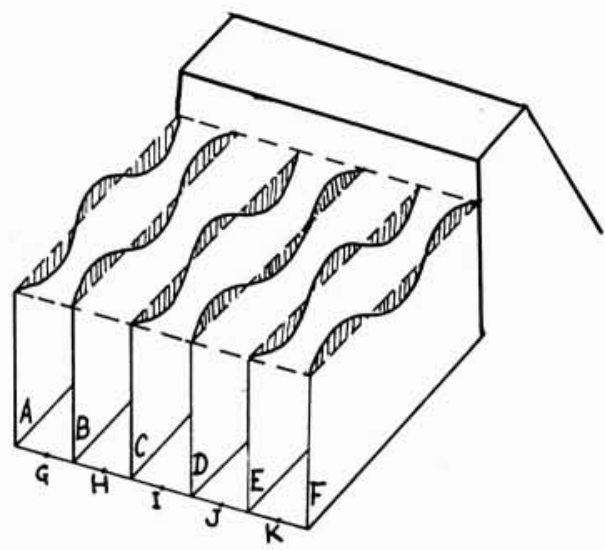

3. Schematic view of incident and reflected waves at a vertical wall. Each pair of waves should be imagined to coexist in the intermediate planes through $\mathbf{H}, \mathbf{I}, \mathbf{J}$. It may be very instructive to cut wave profiles in two pieces of paper, superimpose them and then displace them equally in opposite directions to visualize the relative position of component waves as a function of time.

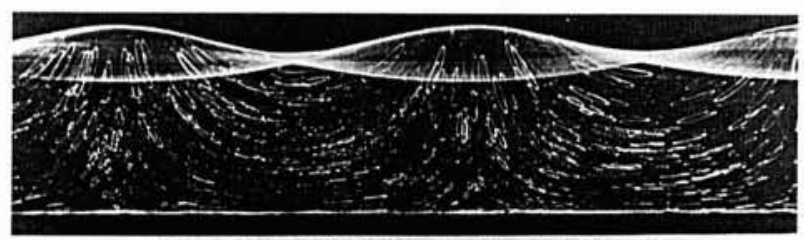
85x relection

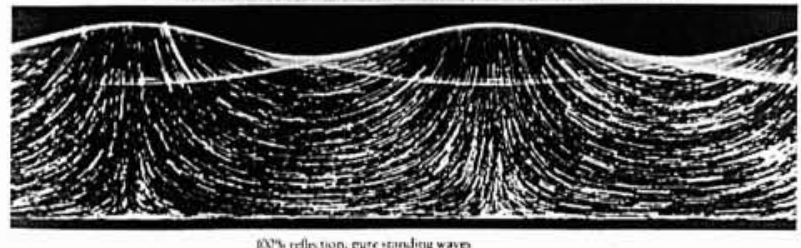

4. Visualization of orbits for partial clapotis (a) and total clapotis (b). (From La Houille Blanche 1950, Wallet and Ruellan).

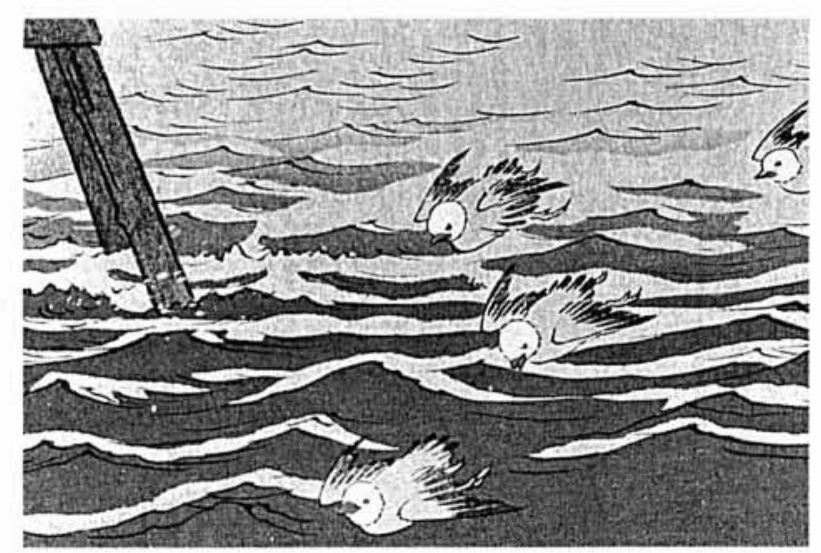

5. Detail from View of Shiba Coast by Hiroshige. Courtesy of Braziller Inc., see One Hundred Views of Edo. water surface that results is called a standing wave; in French, the term, which has become of common use in the technical literature, is " clapotis *. Not all walls produce a perfect, or almost perfect reflection; if some wave energy is lost at the wall, the reflected wave is of less amplitude than the incident wave, resulting on a water movement called partial clapotis.

A simplified analysis of the clapotis may be helpful in understanding its main features and seeking them out in representations by artists. Because in art only the water surface at a given instant is depicted, it may not be easy to distinguish standing waves from propagating waves in paintings. To take into account walls that may absorb part of the energy of the wave, we will define the one-dimensional expression for the superposition of two waves travelling along the $\mathrm{x}$-axis in opposite directions as follows:

$$
b=a_{1} \cos (\mathrm{kx}+\mathrm{ct})+a_{2} \cos (k x-c t)
$$

Herein, $b$ denotes the water surface elevation; $a_{1}$ and $a_{2}$, the amplitudes of the incident and reflected waves; $k$, the wave number ; $c$, wave speed; and $t$, the time. Note the difference in sign in the terms between parentheses, corresponding to the two waves. To take into account the possibility of loss of energy, we assume that $a_{2} \leqslant a_{1}$. To this equation we should add one describing the orbits of the water particles ; if such an equation is used, one finds that precisely under the crests, in the case of total clapotis, the horizontal component is zero at all times, which is the condition at a vertical wall.

In Figures $4 a-b$, we show the results of some experiments at the NEYRPIC Laboratory in Grenoble, France [La Houille Blanche 1950], in which we see the surface profiles and also the internal motion in total and partial clapotis; these orbits agree very well with the ones determined theoretically.

Regular waves are rare in nature, but they may be generated by a boat travelling at relatively high speed; with some luck one can easily observe standing waves for a brief period of time if those waves come upon a wall. Manifestations of partial clapotis are more often seen, because the wall may not be at a right angle with the wave propagation direction. One has a good chance of seeing total and partial clapotis in rivers, canals, and harbors.

Although one would expect clapotis to have been depicted often in paintings, it is not easy to identify the one-dimensional clapotis discussed above. We may be luckier if we look for clapotis in two dimensions, i.e., in the case in which the incident waves impinge on the wall at an angle and are reflected at another angle. For instance, in figure 5, Hiroshige depicted pointed waves that I believe represent a clapotis with an irregular distribution of crests. Let us consider the simpler case in which the incident wave encounters the wall at an angle of $45^{\circ}$ and the reflected wave leaves at an angle of $135^{\circ}$; in this case, we may take the $x$-axis for the direction of the incident wave and the $y$-axis for the reflected wave, and write, for the superposition of the two waves

$$
b=a_{1} \cos (k x+c t)+a_{2} \cos (k y-c t)
$$

Note that, in this expression, $b$ is a function of the two spatial variables $x$ and $y$. Nowadays, one could use a computer to generate a large number of graphs representing wave systems given by this equation, but I have preferred to work with pencil and paper and to use the above expression to arrive at some simple perspectives of these waves, as I did in the second article (see fig. 21 - Article II). This is the sort of picture that one should look for in paintings, although of course not drawn according to the same method. I believe that a view like this, in which one can hardly see the valleys, was first depicted by artists 
of Medieval times and the early Renaissance. What stands out to the eye, when water is observed at fairly low angles, are the crests, and not the valleys. This simple observation is probably the explanation for the way that the stormy seas of Monreale's mosaics and Giovanni di Paolo's painting are depicted (respectively fig. 7- Article I and fig. 23-Article II). I found that one has to make an effort of imagination and observation to see that there are valleys of exactly the same shape, if one uses sinusoidal waves to describe this phenomenon.

The superposition of the incident and the reflected waves leads to an increase of amplitude with no change in wavelength, and this tends to produce more steepness at the crests. For large resulting amplitudes, this may lead to instability and breaking of the waves. To this, the effect of the wind can be added and breaking may result even earlier. These conditions can be found often in paintings; one early example is given in figure 6.

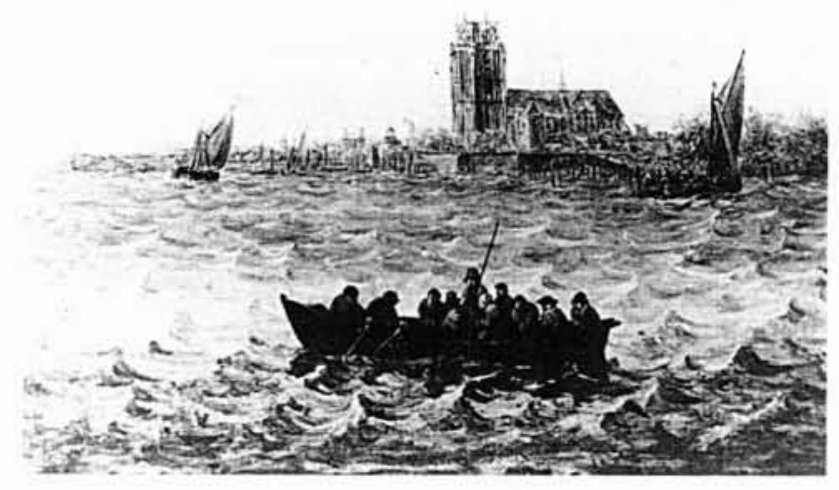

6. Detail of Blick über die Meerwede auf Dordrecht, by Jan van Goyen. By permission from Kunsthistorische Museum, Wien.

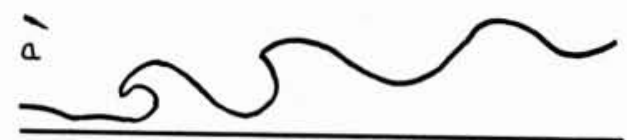

b

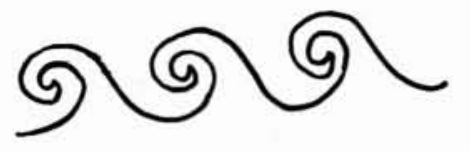

7. Profile of a plunging breaker by Leonardo da Vinci (a) and idealization of the same phenomenon by an Etruscan artist (b).

\section{Waves approaching a beach}

I will now consider progressive waves arriving at a shore with a beach with rather mild slope, a common phenomenon present in so many places where people gather to enjoy a day at the seaside. The wave trains that satisfy those conditions are called - the swell - More accurately, the swell should be described as groups of trains of waves, but for my purpose, we may very well assume that the oncoming waves are regular and sinusoidal. These are conditions that are easier to observe in a laboratory than in nature, but they help to understand the natural phenomenon.
In natural conditions, waves that at some distance are not parallel to the shore line are seen to bend and arrive upon the beach nearly parallel to that line. This tends to simplify somewhat the possibilities and make the events at a beach more or less typical. Hydrodynamicists have found that the bending of the waves can be explained in a relatively simple way. Knowing that the speed of the water waves is a decreasing function of the water depth, they were able to develop a method to compute the bending of the crests of the waves, after discovering that the family of lines orthogonal to the crests lines behave like the light beams when going through media with variable refraction index. The phenomenon was therefore designated as the refraction of water waves and the orthogonal lines were called the wave rays. The effect of refraction becomes noticeable as the water depth under advancing waves approaches the order of the wave length.

According to the above, an understanding of the simple case of wave crests parallel to a straight coast line, with a beach of mild uniform slope, should suffice to deal with many different situations at the beach. In this ideal case, there would be no bending but, as the waves move over the beach, their fronts get closer and closer to each other. This entails an increase of energy per unit length in the direction of the wave rays, while the waves become steeper and higher, losing their sinusoidal form. As the process continues, the crests approach the limiting shape, and beyond that, they become unstable and break in different way, depending on the slope of the beach. Leonardo da Vinci already observed this phenomenon, but he depicted only the initial phase of the breaking of the crest (fig. 7a). In the accompanying text, however, he described the main phases of this phenomenon :

The sea wave that approaches the beach breaks on it with impetus. After breaking, it consumes its impetus as it runs over the beach. In turning back, it impacts the base of the next wave and slows it down. As the upper part of the wave travels faster than the lower part, it will find itself without support and then it will fall over the lower part; after breaking, it enters under the foam which is left behind. This foam moves in opposite direction to the lower part of the following wave. (Codex Madrid II 64R).

Here we see that Leonardo described the breaking of waves approaching a beach as a scientist, both in his comment and in his sketch, which consist of a cross-sectional view of the unsteady phenomenon. I have examined all his existing paintings, and I could not find any artistic depiction of breaking waves. In fact, this kind of depiction by artists seems to belong to a somewhat later period, unless we want to look at stylized depictions like the one reproduced in figure $7 b$ as inspired by a wave like the one depicted by Leonardo. The sketch in figu$r e 7 b$ is from an Etruscan funerary slab [HÖ́cKMANN 1985].

The breaker described by Leonardo has been called the plunging breaker. He correctly assessed the dissipation of energy by turbulence in this kind of breaker. We can understand that this results in partial or total elimination of reflected waves depending on the amount of dissipation. In the sea, beyond the breakers, we can expect to see progressive waves little or not affected by reflection.

Before we examine other kinds of breakers, I would like to mention to the reader some books which deal with waves in an attractive elementary manner, using very good illustrations; rigorous treatises of waves are of little help in this respect. The books that have been very useful to me in developing some of the notions I am presenting in these articles are those by CORNISH [1934], Bascom [1964], Barber [1969], Crapper [1984] and Trefil. [1984].

In addition to the plunging breaker, KINSMAN [1984] mentions the spilling breaker. The plunging breaker has a well rounded 

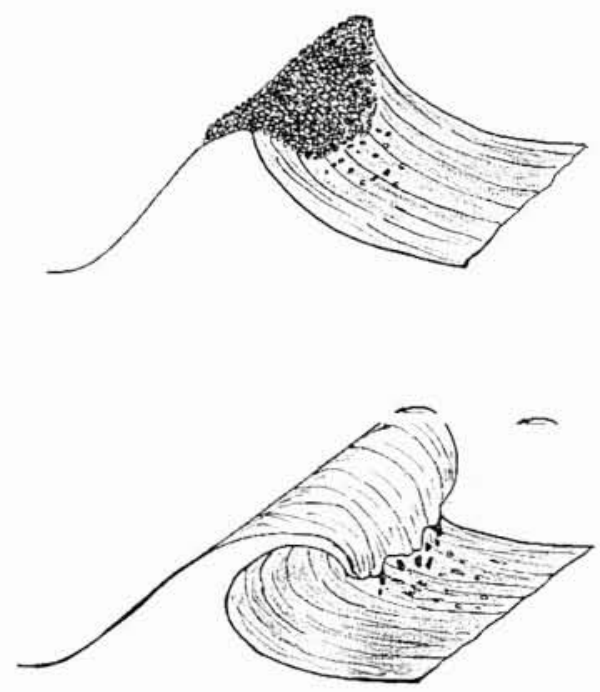

8. Plunging breaker and spilling breaker. Based on illustrations given in Kinsman 1984.
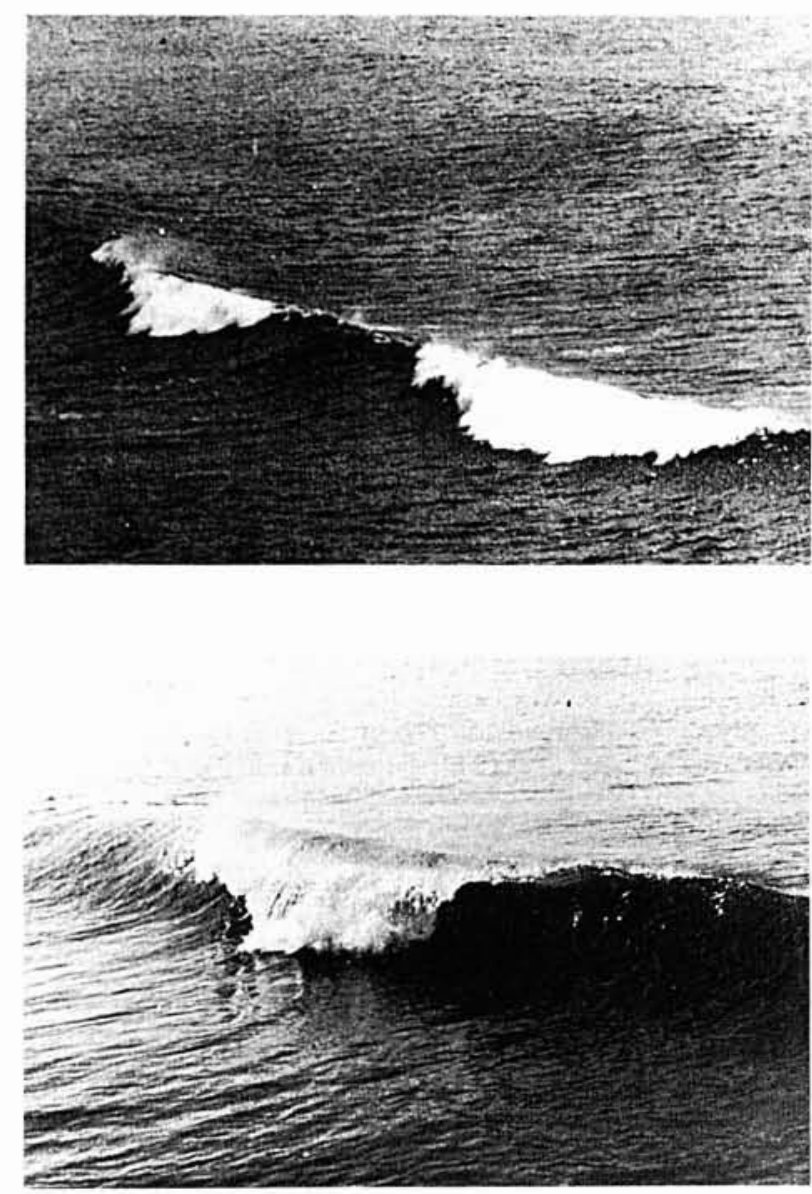

9-10. Photographs of spilling and plunging breakers. Reproduced with permission from Introduction to Water Waves by G.D. Crapper, published in 1984 by Ellis Horwood Ltd., Chichester, England. back and a concave front while the spilling breaker is concave in both phases. Figure 8 shows a somewhat different rendition of an interesting drawing of these two kinds of breakers as originally given in his book. DeAn and DaL.rymple [1984] mention the other two kinds of breakers : the surging breaker, characterized by narrow or no surf zones and relatively high reflection, and the collapsing breaker which they define as a combination of plunging and surging breaker. Spilling breakers are found in very mild sloping beaches and also in high seas; plunging breakers are present only in steeper beaches resulting in a phenomenon very attractive to surfers ; surging breakers appear on very steep beaches.

In papers and books by scientists we commonly find schematic representations usually in the form of cross-sectional views (like Leonardo's). For three of the four types of breakers, there are representation of this kind in DEAN and DaLRYMPI.F. [1984]. Some exceptions are drawings like the ones in figure 8 and that of the cover of paper-back edition of Bascom's book. Of course, in scientific books one finds many photographic illustrations: two are reproduced in figures 9-10.

For readers with an interest in the hydrodynamics of breakers, I would like to mention that there is an ample bibliography, beginning with a pioneering work. Four decades ago, I met the author, Francis Biesel, a French hydraulician who was studying water waves at Grenoble, and had just produced some calculations of this complex phenomenon recorded more than four centuries before by Leonardo da Vinci. Francis Biesel approached the problem of the breaker in the fine tradition of the French hydraulicians who dealt with extremely difficult problems, by cleverly stretching the methods developed for rather simplified conditions to the plausible maximum of their range and even beyond. His profiles are shown in figure 11a, in which we can see the phase just prior to the plunge. Because Biesel used the linearized equations, we cannot expect from his model that it would represent the plunging of the breaker. His calculations played an improtant role as they opened the way towards more accurate computational modeling of the phenomenon. In figure $11 b$, I have included a photograph from an experiment at the Hydraulics Laboratory at Chatou, France, where we can see the physical counterpart to one of the profiles calculated by Biesel.

Many artists have represented breakers ; for instance, centuries ago, van Goyen painted spilling breakers in the open sea very vividly. Among the many seascapes by Turner there are scenes with breakers, as in Down after the wreck. Courbet, in La Vague (fig. 12), gives an almost photographic rendition of a plunging breaker. Johnson HFADE, in Approaching storm. Beach near Newport (fig. 13), depicted a view of a beach with several lines of plunging breakers. Winslow Homer's work includes a number of views of the sea shore and of the open sea with breakers; Cannon rock (fig. 14) offers a rather accurate representation of a spilling breaker in a turbulent sea. More recently, in a beautiful woodcut, Escher depicted breakers in a storm (fig. 15); in his drawing, we can see, among many spilling breakers, one spewing droplets into the air that 1 find very similar to the one in the predella of Giovanni di Paolo ( $f$ ig. 23 - Article II). Moreover, the white lines that Escher drew on the waves may be more than the artist's device and be related to capillary-wave patterns superimposed on gravity waves (see fig. 15 - Article II).

I could not leave out an imaginative work that greatly attracted my attention when I saw it in the Neue Pinakothek of München : Die Rosse des Neptun, by W. CRANE (fig. 16). It describes a plunging breaker where a line of white horses seems to emerge from the sea as metaphors for the water lamina that condenses the energy of the impending breaking of the wave. The special meaning of the term * white horse - can be found in some dictionaries. For instance, in the Random House Dictionary, 

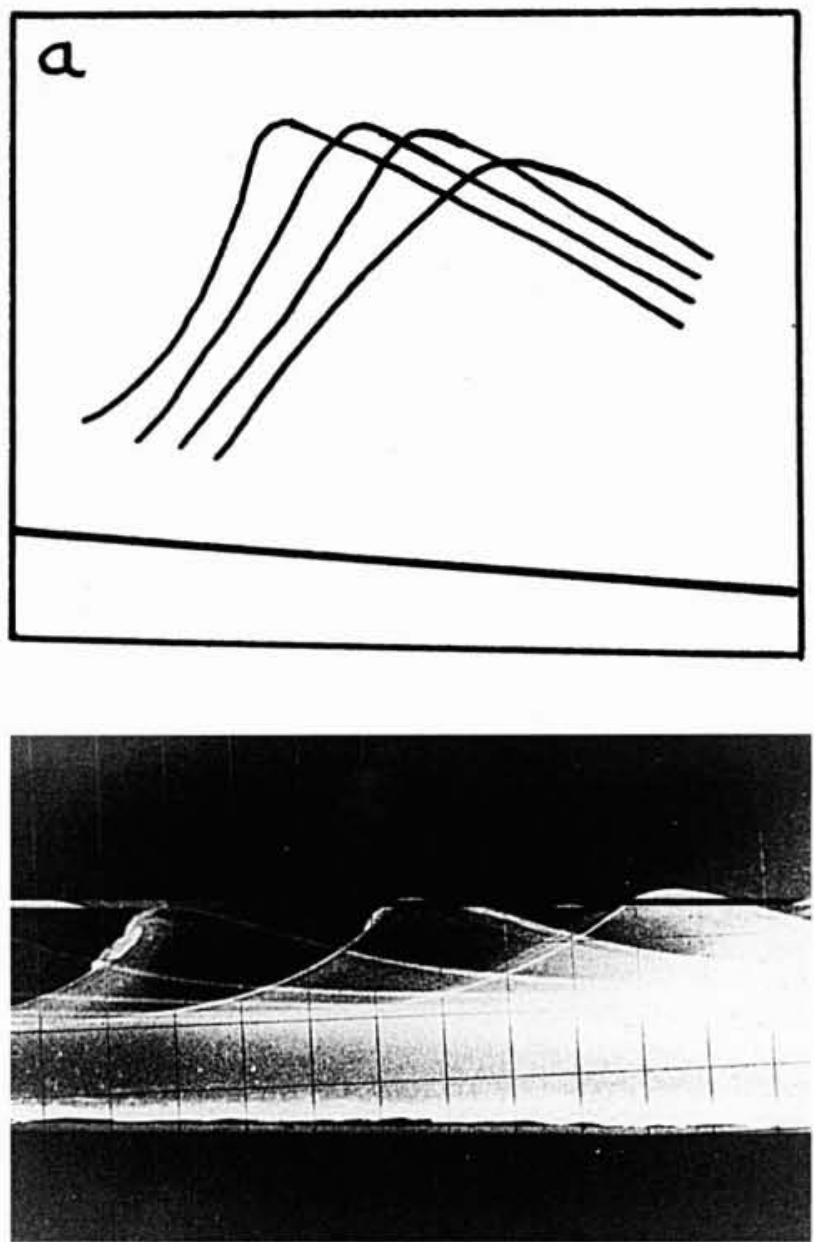

11. Profiles of waves near the breaking point, as determined theoretically by Biesel (a) and by experimenters at the Chatou Laboratory (b). Photograph, courtesy of M. Manoha.

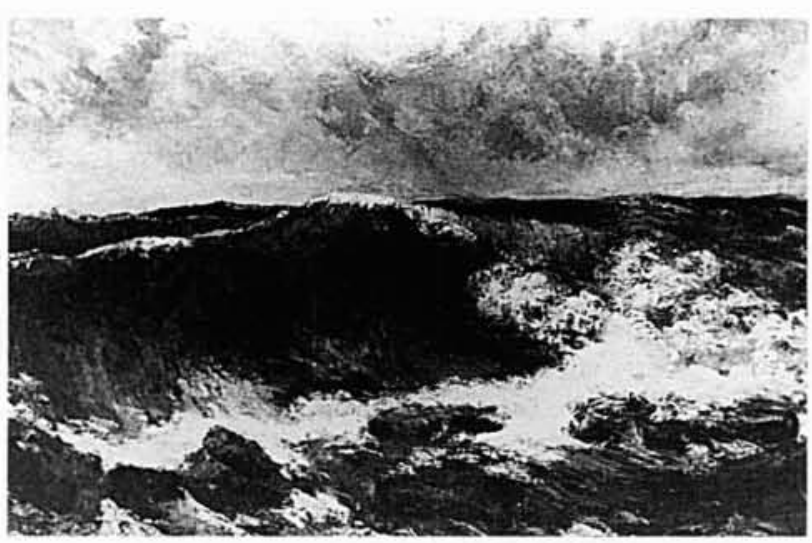

12. Detail from La Vague by Gustave Courbet (1869/70). By permission of Städelsches Kunstinstitut und Städelsche Galerie, Frankfurt am Main.

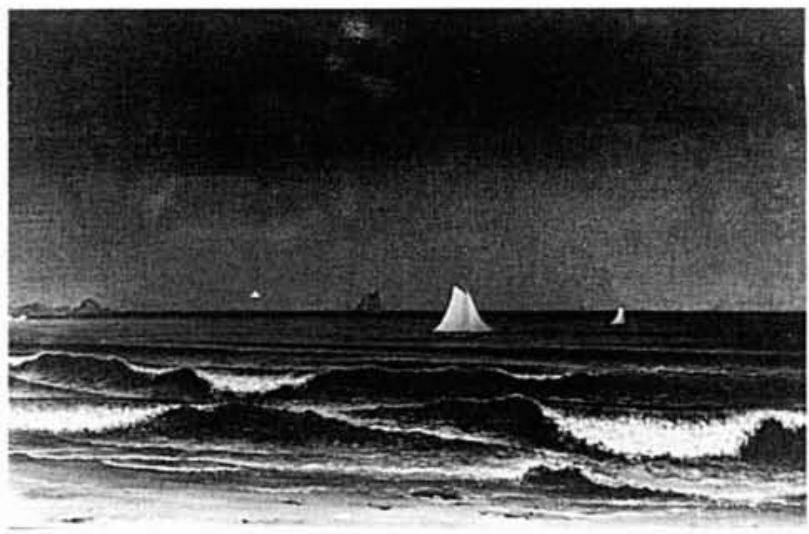

13. Detail from Approaching Storm, Beach near Newport by Martin Johnson Heade, M. and M. Karolik Collection. By permission of Museum of Fine Arts, Boston.

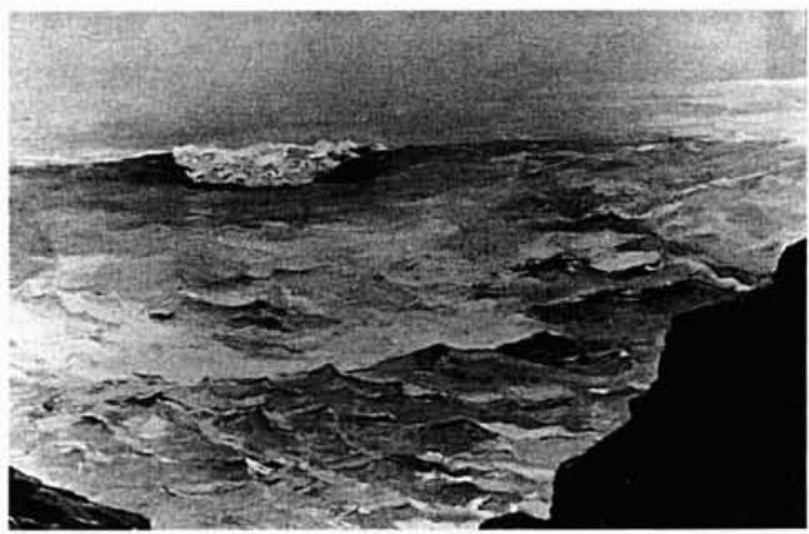

14. Detail from Cannon Rock by Winslow Homer. Compare the clapotis type of waves, at the point of breaking, in the foreground with those in figure 6 . By permission from the Metropolitan Museum of Art, Gift of George A, Hearn, 1906. (06.1281).

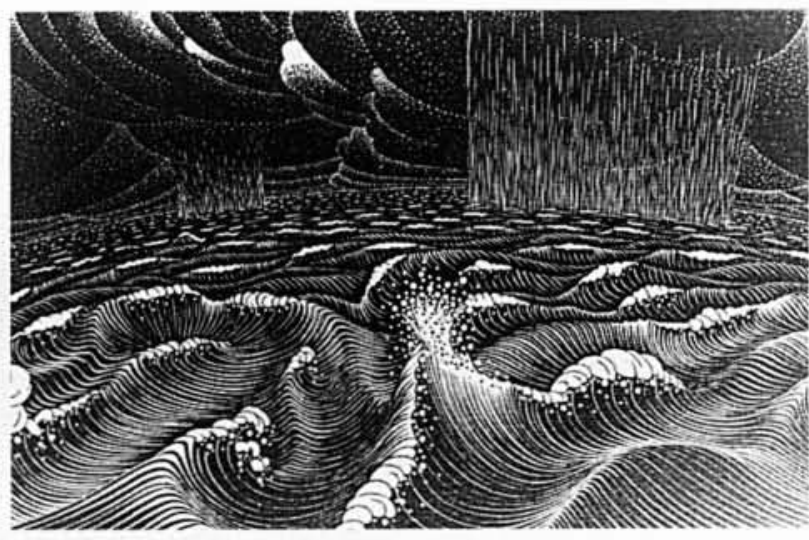

15. Detail from Second Day of Creation, woodcut by Maurits Cornelis Escher. (c) 1925 M.C. Escher / Cordon Art - Baarn, Holland. All rights reserved. Collection Vorpal Gallery, New York (Soho), San Francisco. 


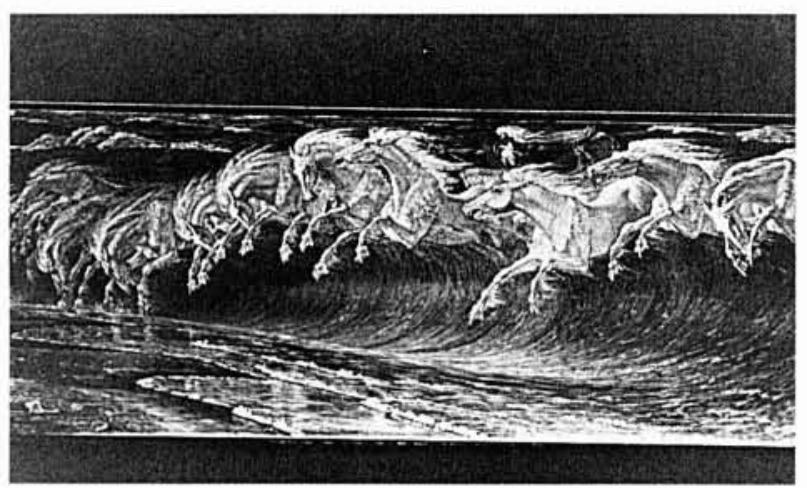

16. Detail from Die Rosse des Neptun by Walter Crane. By permission of Neue Pinakothek, München.

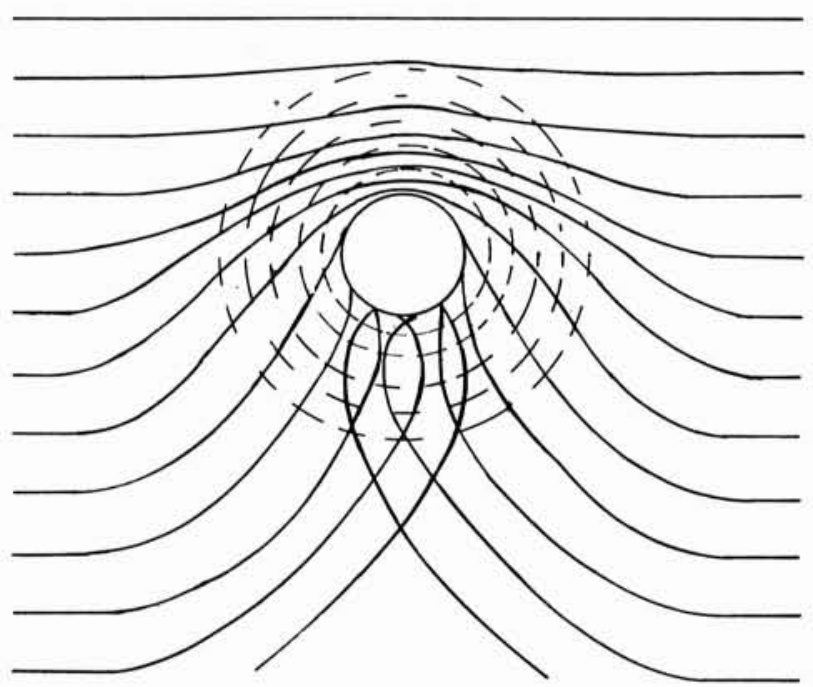

17. Refraction pattern around an island surrounded by a sloping beach. The circumferences are contour lines of the bottom of the sea. Based on drawings by Bascom 1964 and Crapper 1984.

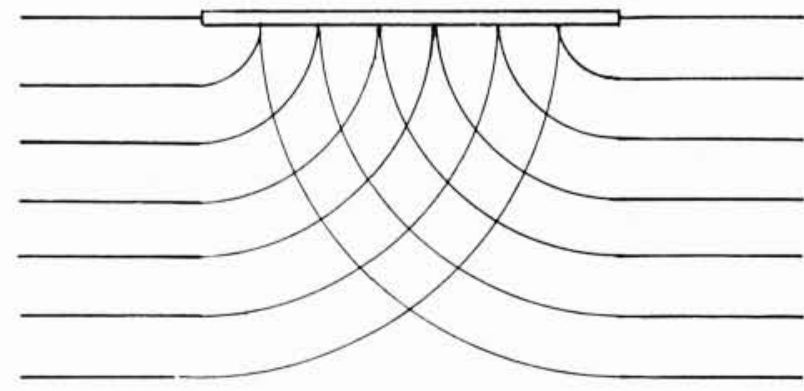

18. Diffraction pattern around an island surrounded by deep waters. Based on a drawing by C.L. Bretschneider, in Estuary and Coastline Hydrodynamics, ed. by A.T. Ippen 1964 .
- white horse - is defined as a white-topped wave or whitecap. In Brewer's Dictionary of Phrase and Fable, "white horse * is described as a poetic phrase for the white capped breakers as they roll in from the sea. In the Webster Collegiate Dictionary, "white horse " is not included, but * whitecap * is defined as a wave crest breaking into foam.

\section{The swell encounters an obstacle}

The phenomenon I am going to consider now has not been frequently depicted by artists. Imagine a wave train moving across the sea or a lake that encounters an island, the edge of a narrow peninsula, or the mouth of a harbor protected by breakwaters. Without complete knowledge about wave propagation, one may be inclined to expect an area that is very well sheltered, similar to the region of shadow behind a large body, like a mountain, receiving light only from one side. BAscom [1964] warns any boatman seeking calmer waters behind an island. This is because, as the waves pass the island, the motion cannot fail to be propagated sideways as well as frontally. Others prefer to speak of energy inevitably propagating around the obstacle, but in a non-technical discussion it seems better to think that wherever the water level happens to go up and down periodically we may consider that point to act as a source, from which motion is propagating.

There are two extreme cases. In one, the island is surrounded by beaches, while in the other, the island is steep-sided all around. In hydrodynamics, differential equations governing waves at the air-water interface have been established and verified carefully. However, it is usually a difficult problem to integrate them to provide us with a good image of particular situations. I prefer to appeal to some simplified approaches and to what experience teaches. We can say that in the first type of island, the waves are subject to refraction as soon as they enter the area of shallow waters surrounding the island. In the second type of island, the waves are subject to diffraction, a phenomenon which has a counterpart in optics, if the obstacle is small compared with the light wavelength. A simple explanation for the diffraction of water waves can be formulated, according to IPPEN [1966], as follows: we can apply Huygens principle for optics to water waves, each point of an advancing wave front can be considered as the center of a component wavelet which propagates out in all directions. This allows us to determine the wave front an increment of time later by tracing the envelope for all wavelets. In figures 17-18, I show representations, by hydrodynamicists, of crests lines, one for each kind of obstacle.

In the cliff-sided island, if it is small and rather round, the rear side is quite disturbed. If the conditions are favorable, e.g., a long island more or less parallel to the wave crests, we have a region that is little affected by the waves. This is used in harbor engineering to design breakwaters that protect ships from stormy waves. What I have said about an island can be extended to other obstacles, like rocks, or ships at anchor. Even for submerged obstacles, we can use some of the above notions to gain some understanding of how they affect the waves.

It is sometimes an interesting exercise to try to discover what kind of wave patterns have been included in a waterscape. In figure 19, I reproduce a detail of a painting by Claude MONET in which he depicted a small island at Chatou. I do not know what the conditions were under the water, but it seems to me that this is an artificial island with vertical walls, and one should expect to see the pattern of diffracted waves, but there may be also a superposition of waves reflected from other walls close to the island.

As 1 have said already, few depictions of this phenomenon can be found, and most show rather complex situations. Interested readers may want to try by themselves to identify situations like those illustrated by the schematically represented 


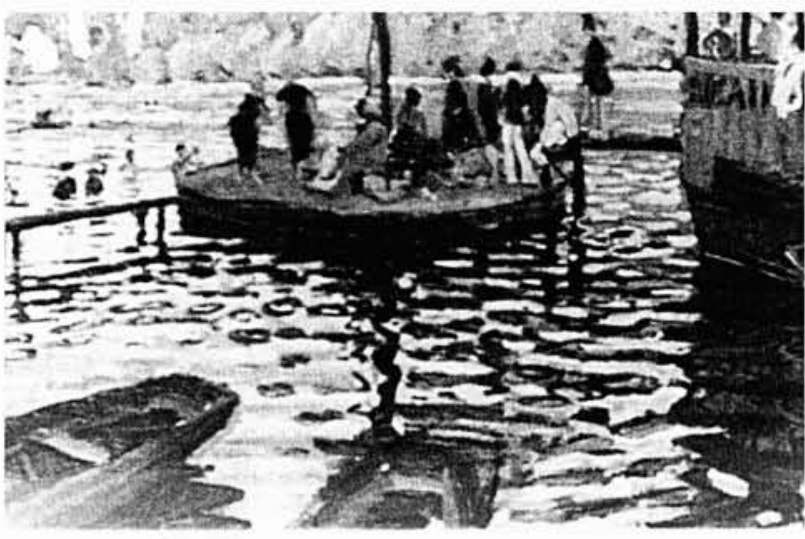

19. Detail of La Grenouillère by Claude Monet. By permission of the Metropolitan Museum of Art, H.O. Havemeyer Collection, Bequest of Mrs H.O. Havemeyer, 1929 (29.100.112).

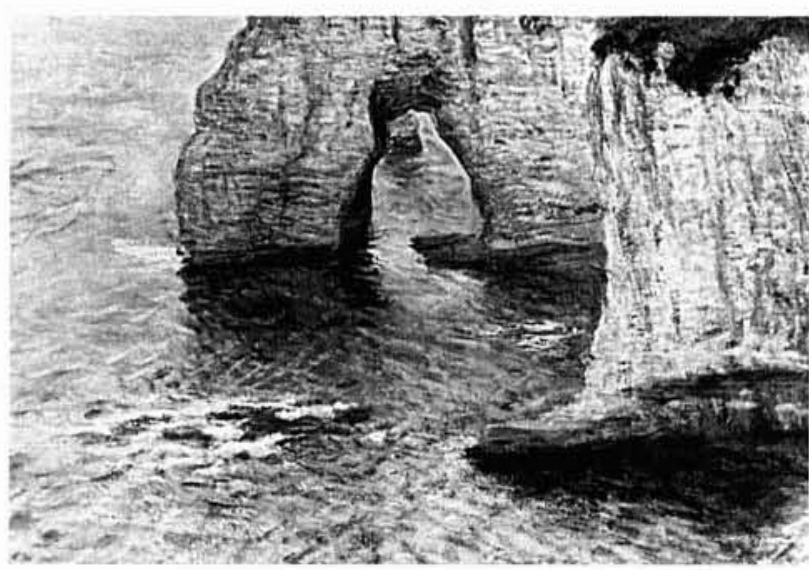

20. Detail of La Manne Porte by Claude Monet, 1885 . By permission of the Philadelphia Museum of Art, The John G, Johnson Collection.

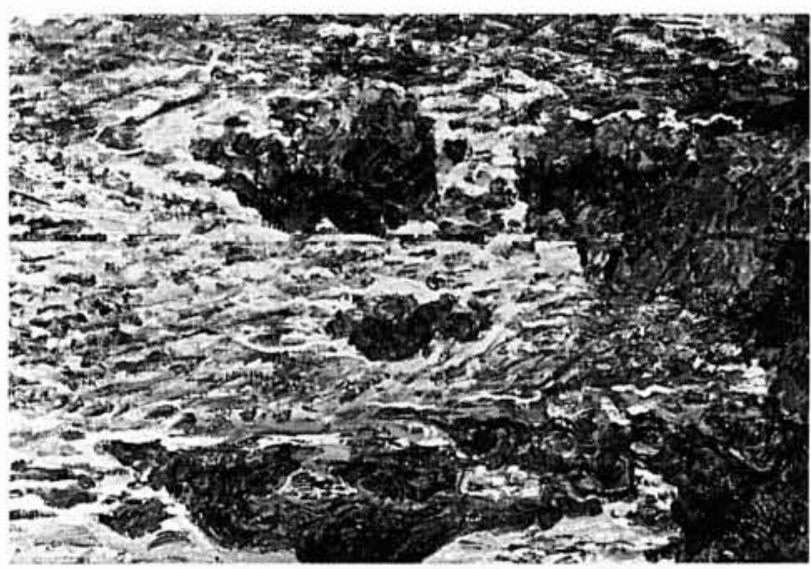

21. Detail of Rocher du lion, Rochers at Belle-Isle by Claude Monet, 1886. By permission of Des Moines Art Center, Purchased with Funds from the Coffin Fine Arts Trust, Nathan Emory Coffin Collection, 1961. systems of waves in figures 17-18. Some Japanese painters have dealt extensively with waves near and around obstacles [See, e.g., Wichmann 1985, in which many depictions by European artists are included.]

Most of the paintings that represent waves encountering an obstacle comprise rocks quite close to shore ; this makes for very complex situations, but sometimes the trained eye can see in a small area a manifestation of one of the situations that are described usually in hydrodynamics as the result of a pure reflection, refraction or diffraction. In most of the paintings one finds a sea that at some distance may seem quite tranquil but, upon coming to the shore, it becomes very agitated and turbulent, with some of the waves breaking as energy is concentrated in small areas (see, e.g., Monet's Storm at Etretat).

1 include two reproductions, from the work of Claude MONET, to illustrate the ideas just expressed. He was inspired by the rocks at the coast, at Etretat and Belle Ile, of which he painted several versions that can be found in some of the most important

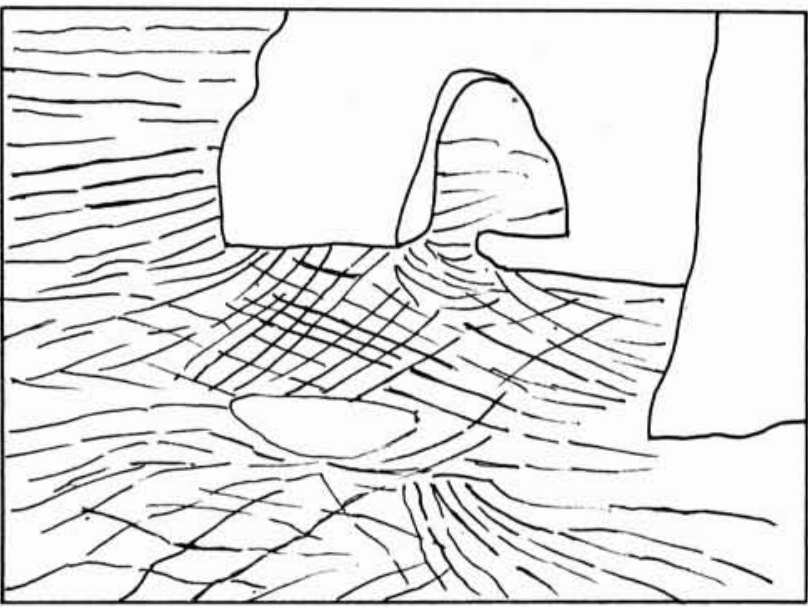

22. Wave lines as perceived by the author in La MannePorte by C. Monet (See fig. 20).

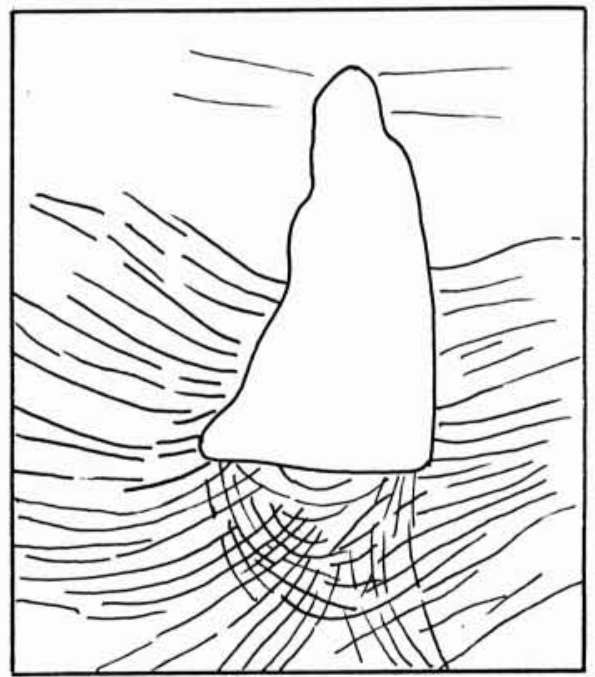

23. Wave lines as perceived by the author in Storm at Etretat, a painting by C. Monet. 


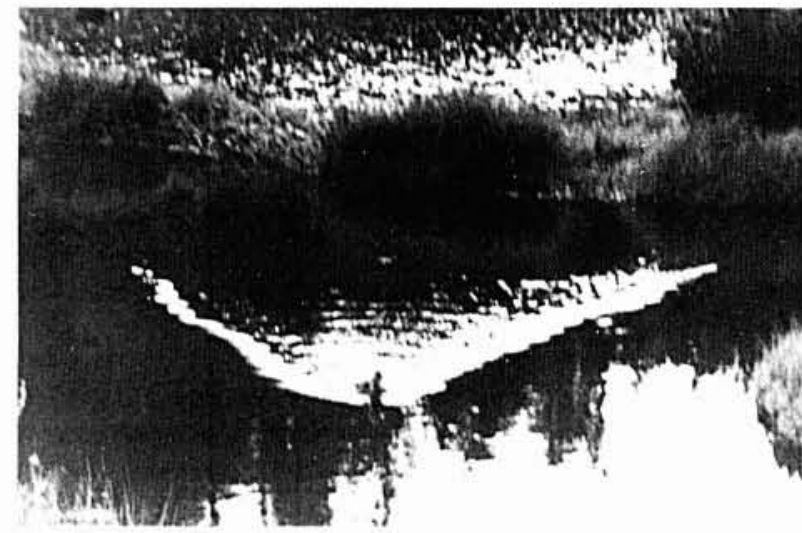

24. Wave pattern produced by a duck. (Photograph by the author).

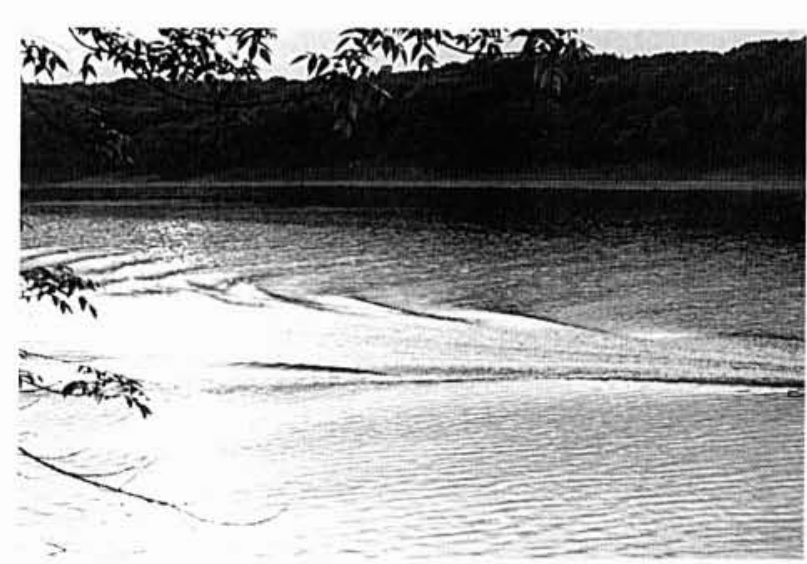

25. System of waves produced by a boat in the Iowa River. (Photograph by the author).

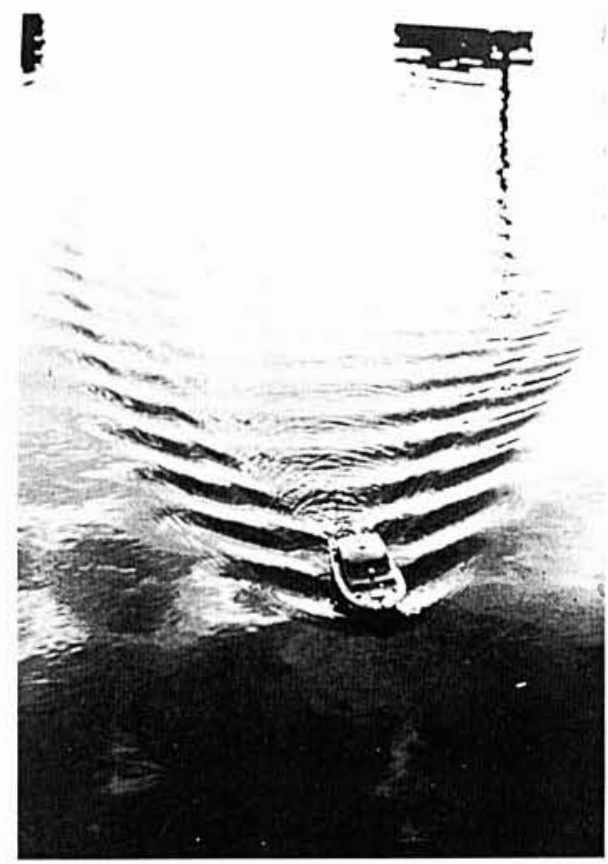

26. Wave pattern produced by the model of a boat on deep water. Courtesy of G.D. Crapper. art museums of the world. In figure 20, a detail of La MannePorte à Etretat is given; MONET represented very vividly the encounter of the waves, coming from a relatively calm sea in the background, with a hollowed-out cliff, surrounding it, and finally crossing each other. Figure 21 shows a detail of Rocher du Lion, Rochers à Belle Ile, with a similar but more complex configuration than that figure 20. In figure 22, I drew my own schematic view of the wave system around the rocks in figure $20 ; \mathrm{I}$ am inclined to consider this as a case of diffraction rather than refraction, although, not knowing the configuration of the boundaries under water, it is difficult to be sure. In figure $23 \mathrm{I}$ have tried to represent the system of waves for Storm at Etretat, which is simpler than that in figure 21. I can add to the examples from Monet's work, some others like Sisley's Langland Bay. The rock and Gauguin's Rocks in the Sea. [See WICHMANN 1985].

\section{Waves produced by boats}

Any objects moving on the water surface, from tiny insects and other animals to boats and large tankers, generate a system of waves. The patterns due to animals have existed for a very long time, even before there were human eyes to see them ; however, one finds them very rarely in paintings. In figure 24,1 show one of those patterns as produced by a duck in a pond ; in figure 25 , the system of waves generated by a high-speed boat in the Iowa River ; in figure 26, the waves around one of the models used by Crapper in his experimental studies. Those systems of waves depend on many parameters, 1 have already mentioned in my second article that water waves are governed by two forces: gravity and surface tension; this alone makes for a complicated phenomenon. In addition, the depth of the water, and the shape, size and velocity of the moving object play also an important role, as we can see by comparing the patterns produced in the three illustrations above. The simplest configurations correspond to the motion of a very small object, which can be considered as a point source of waves.

When a ship moves through water, it generates a system of waves more complex than that produced by a point source. In fact, it produces two systems of waves, whose sources are the bow and the stern. Around the bow, water swells up and the imbalance with the surrounding lower water results in the bow waves (fig. 27a). The other system of waves is due to the depression that is produced around the stern. All the waves generated by the moving hull end up by determining a system

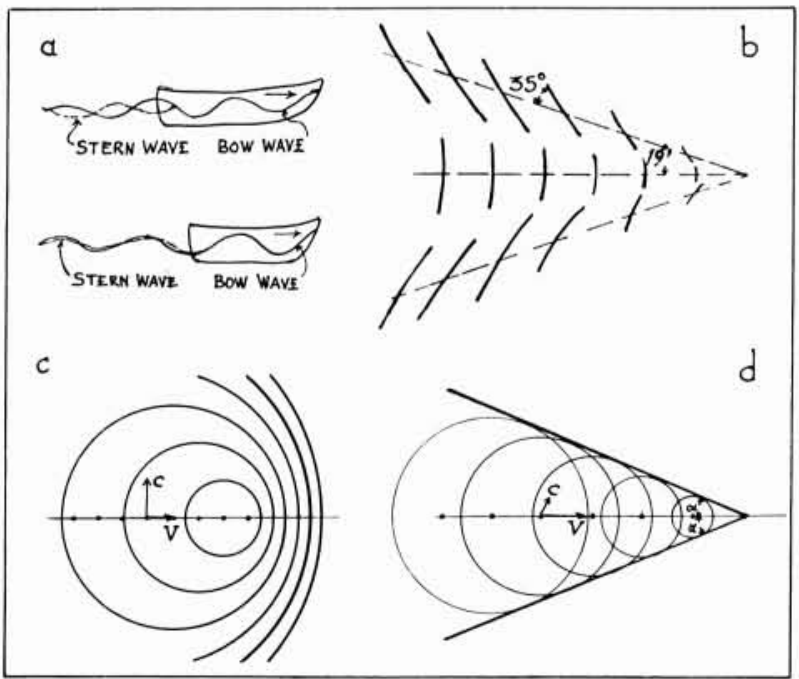

27. Bow and stern waves (a). Waves generated by a ship in deep waters (b). Waves in shallow water (c-d). 
that, when observed from the ship, appears as very nearly stationary ; successive photographs from the air have shown few differences. If the ship stops, the waves continue moving ahead, leaving their source behind. We must also take into account whether the ship is navigating in deep or in shallow waters. Of course, we must remember that in this case also, it is actually the ratio $a / L$ of amplitude over wave length that makes an expanse of water deep or shallow. What is deep water for a duck may be very shallow water for a large boat. I am going to consider only vessels travelling through relatively calm waters; the case in which the ship moves across a water surface with non-negligible existing waves is too complex for simplified explanations, except in the case of low ship speed.

In deep water, three lines of waves, one on each side of the ship's wake, and one along the centerline, can be seen (fig. 27b). The two side lines form an angle that, paradoxically, remains nearly constant around the value of $39^{\circ}$ for different speeds of the ship. Moreover, each wave crest in those lines forms an angle of around $35^{\circ}$ with the respective line. Lord KfLVIN, as early as 1887 , studied these waves using the notion of group velocity. Other hydrodynamicists have dealt with the subject with a less sophisticated mathematical approach, and I would like to refer the reader to the books by BARBER, BASCOM, Crapper, and Tricker.

When the water is shallow, the angle between the two side lines of waves becomes dependent on the speed of the vessel. Of course, there is a whole range of different cases for intermediate values of $a / L$, in which a mixed behavior is found. In figures $27 c-d$, I illustrate schematically the scientific views of the two extreme cases of waves generated by ships in uniform motion in calm shallow waters

In artistic representations of ships, one can find an early period in which it seems that the artist began by representing the ship and then depicted the waves following his received knowledge about the way of covering an area with the symbols of water (remember the ubiquitous triangular wave of the Egyptians, or the trochoidal wave of the Assyrians in Article I). This seems to be what happened with the ships shown in Trajan's column in Rome, as well as in other ancient representations by Assyrians, Egyptians, Greeks, and Mayans.

That approach seems to survive in some Medieval and early Renaissance depictions, and even in present day simplified illustrations, which consist of the contour of a ship and a few wavy lines below. This is precisely what we find in the Bayeux Tapestry [c. 1080] and in Gentile da Fabriano's Quaratesi Altarpiece [1425]. Still rather simplified are the waves in an illustration by G. GIRALDI [1458] of the works of Virgil (fig. 28a). Also very sketchy are the waves along the hull of a boat in Fishermen in a mountain lake by MoтоNовU [c. 1540], but he inverted the profile with pointed crests. The wave profile along the hull of a ship in one of a group of paintings by the Masters of Köln [1450-60] depicting the arrival of St. Ursula to that city, one can see a remarkable feature with crests which break only alternately (fig. 28b); it is remarkable that a similar profile (fig. 28c) was found theoretically by PIERSON [1962] when superposing Gerstner's waves. In figure $28 d$, I give a sketch of the waves depicted by Leonardo da Vinci around a sailing boat; the waves along the hull resemble those of Giraldi, but he added an exaggerated piling of waves in front of the bow. A family of nearly concentric waves around the bow of a boat can be seen in the Da Costa Hours [Bening and others, c. 1515]. In figure 29, a detail from a painting by Cranach the Older [1529] contains waves around a boat and also those around a swimming deer, especially those ahead of the animal. There is a similar painting by Cranach the Younger. Sometimes it is difficult to imagine what circumstances may have produced the waves in a painting, as in the case of a picture by Signac of a ship in front of the port of La Rochelle (fig. 30); maybe the ship bounced under a gust of wind, or they
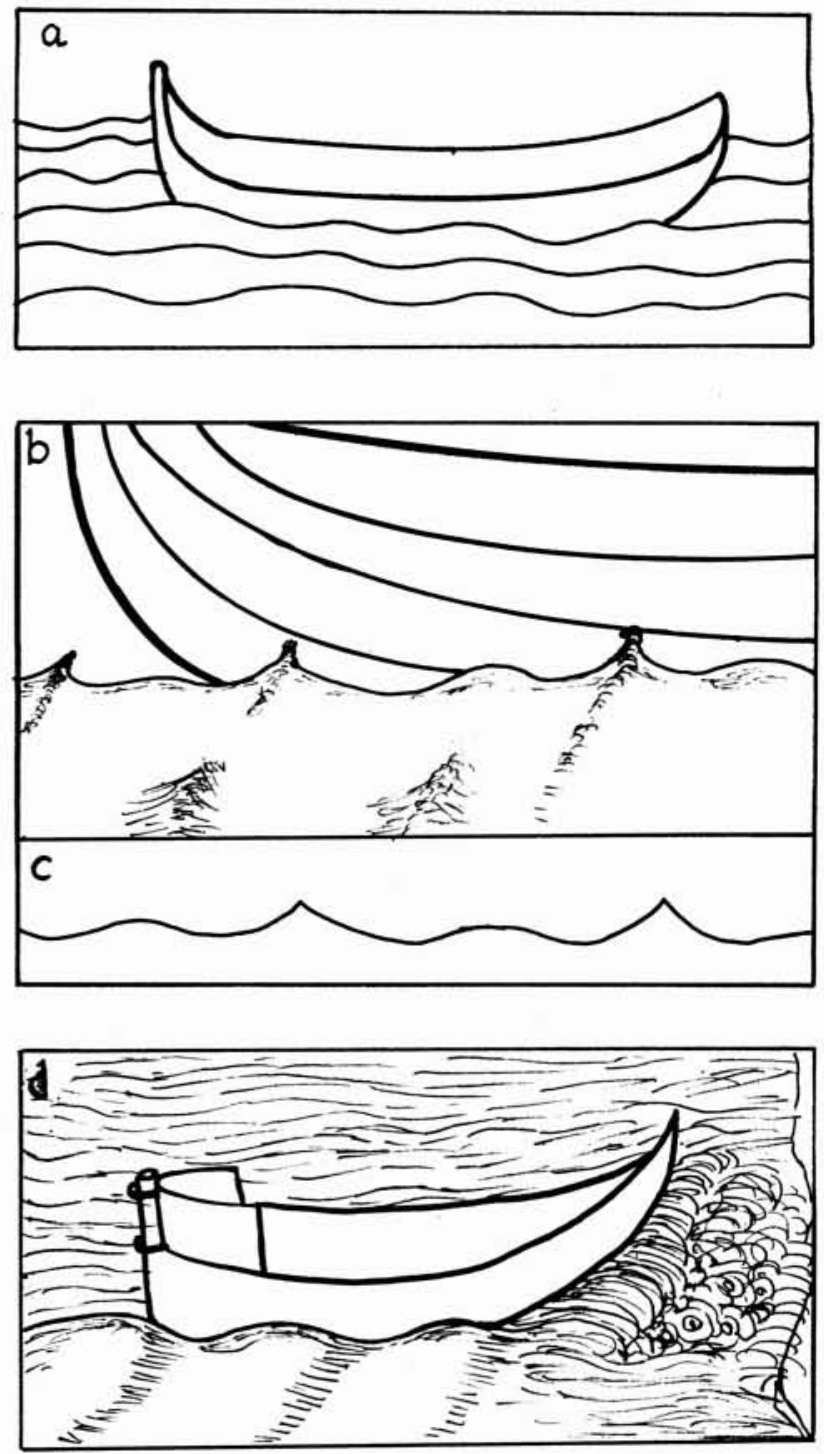

28. Sketches of waves around boats from depictions by G. Giraldi (a), Masters of Köln (b) and Leonardo da Vinci (d). Waves determined theoretically by W.J. Pierson 1962 (c), to be compared with those in b.

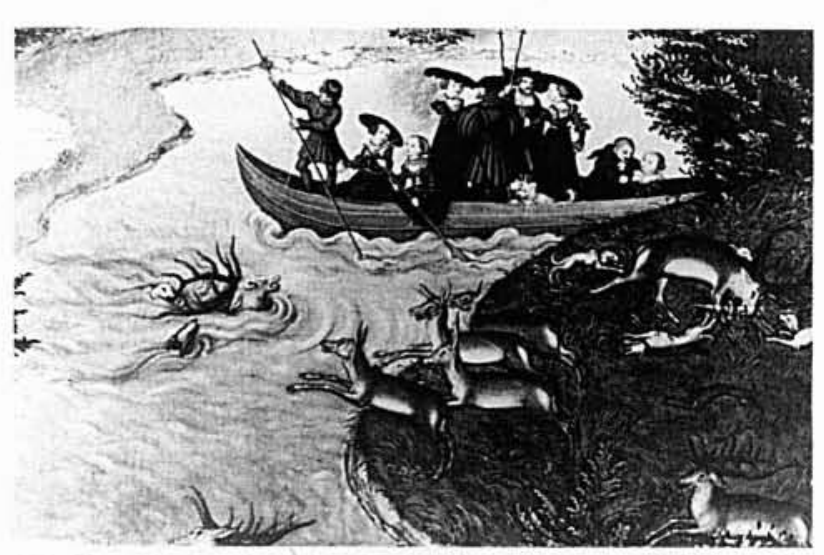

29. Detail of Hirschjagde des Kurfürsten Friedrich des Weisen by Lucas Cranach d. A. Note the wave systems around the boat and the animals. By permission of Kusnthistorisches Museum Wien. 
are waves similar to the ones in figure $27 c$. In figure 31 we see a detail fo one of Manet's versions of LEvasion de Rochefort [1880-81] in which the wake is at an angle, most likely because of the boat making a turn. In more recent paintings, one finds more and more realistic depictions, not too different from what photographs may reveal. However, some wave patterns, as those of figure 27 , are not easily found in paintings for either ducks or ships.

\section{Conclusion}

In this article, the water phenomenology has become much more complex, and the variety of patterns on the water surface is immense. Therefore, I have chosen for this article those configurations that have been more frequently depicted by

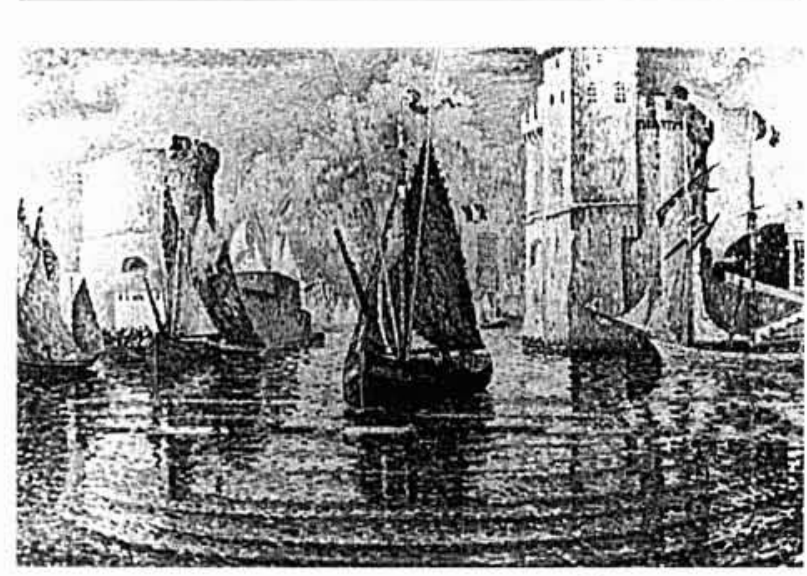

30. Detail of Port de la Rochelle by Paul Signac. Note especially the nearly concentric waves. This is a an interesting case of water as a mirror. (c) 1993 ARS, New York/SPADEM, Paris. (c) Photo R.M.N.

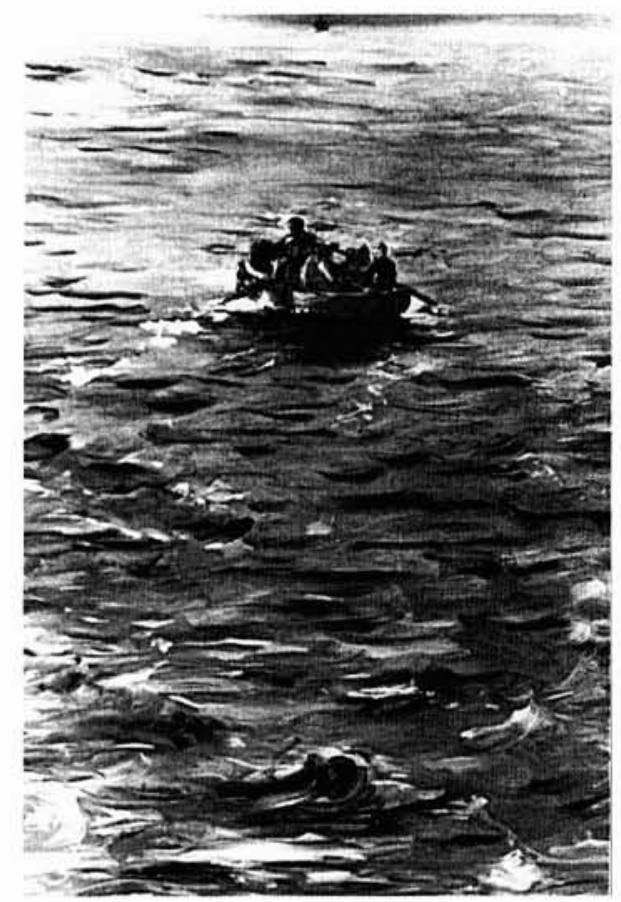

31. Detail of L'Evasion de Rochefort by E. Manet. Observe the strange unreal shape of the wave in the foreground. By permission of Musée d'Orsay, (c) Photo R.M.N., Paris. artists and studied by scientists, so that there is more material to be compared. Even so, as one progresses from waves arriving at a wall and those running over a rather regular beach to waves going around islands, peninsulas or groups of rocks and those generated by ships, the difficulties increase and some limitations become more and more demanding. On the one hand, it is remarkable that the area in which $I$ have been able to find more examples of artistic representation is the case that is really more complex, which is that of objects moving through existing waves while they are generating their own wake of waves. On the other hand, the bulk of representations by scientists is for rather simplified conditions. I hope, in the near future, to deal with these topics in a more extensive way than in this brief article.

\section{Acknowledgements}

I am very grateful to many persons with whom I have discussed my project, and from whom I have received encouragement and critical advice, especially to Profs. Ernst Gomiseich, Mauricio Lasansky, Carlo Maccagni, Pietro Marani, Enzo Macagno, David Topper, and Wallace TOMAsini. Prof. Eduardo MACAGNo read the manuscript and offered valuable comments.

Credit for fee-authorizations is given with each figure. The participating institutions are the following: The Metropolitan Museum of Art (figs. 2, 14, 19), Kunsthistorische Museum Wien (figs. 6, 29), Städelsche Kunstinstitute Frankfurt am Main (fig. 12). Museum of Fine Arts Boston (fig. 13), Neue Pinakothek München (fig. 16). Philadelphia Museum of Art (fig, 20), The Des Moines Art Center (fig, 21), ARS New York/SPADEM, Paris (fig. 30), Musée d'Orsay, Paris (fig. 31).

Special thanks go to those who granted permission without charge for my illustrations: M. MANOHA, EDF, Chatou Hydraulic Laboratory (figs, 1 . 11b), G. Braziuer Inc. (fig. 5), Ellis Horwood Lid., (figs. 9, 10, 26), Cordon Art B. V., Holland (fig. 15)

The Department of Mathematics of the University of lowa provided encouragement and support during the long period of preparation of this series.

\section{References}

These references are divided in two sections: 1. Books and articles, and 2. Paintings and drawings. This is done because paintings and drawings are as important as papers, and because more than reading books and papers, my readers should look at depictions of water by artists and drawings by engineers and scientists if they want to pursue this initial study of Aqua Depicta.

\section{Books and articles}

BARBER N.F. (1969), - Water Waves, Wykeham Publ., London. A subsidiary of Taylor \& Francis L.td. London and Winchester.

BAscom Willard (1964), - Waves and Beaches. The Dymamics of the Ocean Surface. Doubleday and Co., Garden City, New York.

Bouasse H. (1924). - Houle, Rides, Seiches et Marées. Delagrave, Paris.

CORNISH Vaughan (1934). - Ocean Waves and Kindred Geophysical Phenomena. Cambridge University Press. Additional notes by Harold Jeffreys (pp. 121-159).

Crapper G.D. (1984). - Introduction to Water Waves. Ellis Horwood Lim. Publ., Chichester, a div. of John Wiley and Sons. New York.

Crapper mentions that, as the wave finds shallower and shallower water, there is a drag from the bottom ; this is true, but it is not the important effect. The wave behavior at a beach can be accounted within a theory in which drag is neglected. In fact, it is the radical change in the geometric boundaries that forces the wave to behave in quite different ways. The change in depth may appear as gradual but the wave travels relatively fast, and rapidly finds entirely different depths and reacts by responding with different velocities of propagation; it becomes shorter and steeper. We know that the waves with large ratio of amplitude to length become more pointed (high short crests and long shallow valleys). This leads to the free surface profile depicted by Leonardo. 
CrAPper G.D. (1957). - An exact solution for progressive capillary waves of arbitrary amplitude. Jour. Fl. Mech. 2, 6.

Deacon G.E.R. - Ed. Oceans. Paul Hamlyn, London.

DEAN Robert G. and DALrymple Robert A. (1984). - Water Wave Mechanics for Engineers and Scientists Prentice Hall, Englewood Cliffs, NJ.

Representations in cross-sectional views of spilling, plunging and surging breakers are given in figure 4.22

DeCrosse Anne (1991). - Toute leau du monde. Du May, Paris (See p. 136).

GERSTNER (1802). - Theorie der Wellen. Abhand. d. k. böm. Gesell. d. Wissen. Prague

Hoeckmann Olaf (1985), - Antike Seefahrt, Verlag C.H. Beck, München.

This little book is full of illustrations of ancient ships ; many of them surrounded by waves which seem to have been introduced more as a symbol of the state of the surrounding sea than as a representation of actual interaction between ship and water dynamics.

HOOKE Robert (1667). - Micrographia.

IPPEN A.T. et al., (1966), - Estuary and Coastline Hydrodynamics. McGraw-Hill, New York.

See simple diagrams for refraction and diffraction of waves with elementary explanations

IrIBARREN CaVANILIEs Ramón (1954). - Obras Maritimas, Oleaje y Diques. Editorial Dossat, Madrid.

This book is an engineering treatise, but it contains, as many others of the same period, a good deal of information on waves, and a certain preference for Gerstner's approach to wave theory. For some time, at least, engineers were not concerned by Gertsner's solution being rotational rather than within the frame of potential flow. The book begins with a remarkable photograph of a series of waves that have been curved into ares of curves nearly parallel by refractive effects as they approach the shore.

KFLVIN Lord (Sir W. Thomson) (1887), - On the waves produced by a single impulse in water, or in a dispersive medium. Proc, Royal Soc: London, Ser. A, vol. 42

Kinsman Blair (1984), - Wind Waies. Their Generation and Propagation on the Ocean Surface. Dover, New York (First publication in 1965).

A reference to whitecaps is on p. 19. Waves which break in whitecaps at sea something quite different from waves that break at the shore.

LAMB Horace (1945), - Hydrodynamics. Dover, New York.

LEBLoND Paul H. and MrsAK Lorenz A. (1978), - Waves in the Ocean. Elsevier Scientific Publ. Co. Amsterdam.

A reference to whitecaps is in on p. 505. White capping at sea and breaking on the shore are without doubt one of the most fascinating features of surface gravity waves. They occur with such violence as to make their study and analysis extremely difficult.

LONGUEST-Higgins M.S. (1973). - On the form of the highest progressive and standing waves in deep water. Proc. Roy. Soc. A 331. 445.

MidDifton W.E.K. (1965), - A History of the Theories of Rain and Other Forms of Precipitation. Franklin Watts, New York.

PIERson W.J. (1962), - Perturbation analysis of the NavierStokes equations in Lagrangian form with selected linear solutions. Journal of Geoph. Res., vol. 67.

Pierson studied the superposition of waves within the frame of Gerstner's theory [1802], and found a result similar to the one depicted by the Masters of Köln in the 15th century, as described in this article.

STOKER J.J. (1957), - Water Waves. The Mathematical Theory with Applications. Interscience Publ. Inc., New York.

SVERDRLP H.U., JoHNSON M.W. and Fleming R.H. (1946), - The Oceans, Prentice-Hall, New York.

TreFIL James S, (1984), - A Scientist at the Sea Shore. Macmillan. New York

TOPper D.R. (1980), - On Abstraction as Concept and Process in Art and Science. Publ. in Perception, Cognition and Representation 1I: Presentations on Art Education
Research, no. 4. Ed. by E.L. Sacca and J.J. Victoria. Montreal. Concordia University. Canada.

TOPPER D.R. (1990). Natural Science and Visual Art : Reflections on the interface. Publ. in Beyond History of Science. Essays in honor Robert E. Schofield. Ed. by E. Garber, Bethlehem, Lehigh University Press.

Although these two articles do not refer to representation of water, the ideas on the interface between ant and science of Prof. Topper may be of interest to the reader of Aqua Depicta.

TRICKER R.A.R. (1965), - Bores, Breakers, Waves and Wakes An introduction of waves on water. American Elzevier Publ. Co., New York.

Wallet A. and Ruelinn F. (1950). La Houille Blanche, no. 4, July-August 1950.

\section{Paintings and drawings}

BAyeux TAPEStry (1080). - This unique document, $231 \mathrm{ft}$ long, is preserved in the Cathedral of Bayeux, France. Sec The Bayeux Tapestry, by John J, Coolingwood Bruce, Dorset Press, New York, 1987. The illustrations in this book are taken from La Tapisserie de Bayeux, Editions Variorum, Paris 1838

BENING and others (1515). - St. Mark in bis study, in the Da Costa Hours. Bruges. Ms. 399, Pierpont Library.

This may be an early example of nearly concentric waves as those in figure $27 c$ due to an object moving at low speed.

Butuin Martin (1985), - Turner at the Tate. The Tate Gallery, London.

A good number of the paintings reproduced in this book are waterscapes.

Cranach Lucas (1529). - The Elector's Frederick of Saxony Stag Hunt, Kunsthistorisches Museum, Wien.

FABRinNo Gentile da (1425). - Saint Nicholas saves a stormtossed ship. Predella panel from the Quaratesi altarpiece, tempera on poplar. The Vatican Collections. Rome.

GIRALDI Guglielmo (1458). - Eneas and the Sybil in Charon's boat. In Oeuvres de Virgile. Bibliothèque Nationale, Paris, Ms latin A, fol. 128.

LÉONARDO da VINCI c. (1490-1500), - The Codices Madrid, Biblioteca Nacional de Madrid. Facsimile publication by McGraw-Hill, New York 1974.

LEONARDO da VINCI c. (1515-16). - Allegory with wolf and eagle. Windsor 12496. (See Leonardo da Vinci, by Martin Kemp et al., (1989) Yale University Press, p. 155)

Another interpretation is about wolf (dog?) and olive tree (See Leonardo da Vinci on Plants and Gardens by W.A. Emboden (1987). Others consider this as an allegory of river navigation.

MANET Edouard (1880-81), - L'Evasion de Rochefort. Musée d'Orsay, Paris, and Kunsthaus, Zürich

The version in Zürich shows a more agitated sea around the boat, but the wake is more pronounced in the one in Paris.

MASTERS of KöLN (1450-60), - The arrival of St. Ursula and her companions. Walbraf Richard's Museum, Köln.

MotonoBu Kano (1540). Angeln in einem Gebingsee, Muromachi Zeit, Japan. Museum für Ostasiatische Kunst, Berlin.

Wichman Siegfried (1985). - Japonisme. The Japanese influence on Western Art in the 19th and 20th Centuries. Park Lane. New York.

Many illustrations in this excellent book are useful to observe depictions of water movement as depicted by artists of Japan and the West. One of the sections is entitled. The wave - and another - Rocks in the sea - There are certainly historical cases of Western artists with deep interest in the Japanese art, but perhaps instances of the same universal topic depicted in two civilizations in similar manner is no proof of influence one way or the other. 